\title{
DISPOSITIVO BASADO EN IONIZACIÓN PARA LIMITAR LA \\ TRANSMISIÓN AÉREA DEL COVID-19
}

\author{
Air ionization-based device to limit airborne \\ transmission of COVID-19
}

EPISTEMUS

ISSN: 2007-8196 (electrónico)

ISSN: 2007-4530 (impresa)

\section{Jesús Pacheco ${ }^{1}$ \\ Víctor Benítez ${ }^{2}$ \\ Benjamín Gutiérrez ${ }^{3}$ \\ David Vidal 4}

Recibido: 23/02/2021

Aceptado: 22/04/2021

Publicado: $25 / 05 / 2021$

DOI: https://doi.org/10.36790/epistemus.v14i28.133

Autor de Correspondencia:

Dr. Jesús Horacio Pacheco Ramírez

Correo:jesus.pacheco@unison.mx

\section{Resumen}

Esta investigación busca demostrar la efectividad de un dispositivo de ionización de aire para limitar la transmisión aérea del COVID-19. Para evaluar su efectividad, primero se probó en un ambiente controlado donde el microorganismo Vibrio parahaemolyticus fue diseminado para verificar el comportamiento en condiciones normales y después bajo la influencia del dispositivo para comparar la carga ambiental del microorganismo. Una aproximación similar se utilizó en una institución de salud, donde el SARS-CoV-2 fue primeramente confirmado colocándose después el dispositivo. Los resultados muestran que, en la institución de salud, la carga viral se puede reducir en hasta un $80 \%$ en sólo 20 minutos. Con la evidencia obtenida de los experimentos se puede concluir que la presencia de iones negativos ayuda en reducir la carga viral del SARS-CoV-2 en el ambiente, y en consecuencia se limita la transmisión aérea del COVID-19.

Palabras clave: COVID-19; SARS-CoV-2; transmisión aérea; ionización del aire.

\section{Abstract}

This research seeks to demonstrate the effectiveness of an air ionization device in limiting the aerial transmission of COVID-19. To evaluate its effectiveness, it was first tested in a controlled environment where the microorganism Vibrio parahaemolyticus was disseminated to verify the behavior in normal conditions and then under the influence of the device to compare the environmental load of the microorganism. A similar approach was used in a health institution, where SARS-CoV-2 was first confirmed and then the device was placed. The results show that, in the health institution, the viral load can be reduced up to $80 \%$ in just 20 minutes. With the evidence obtained from the experiments it can be concluded that the presence of negative ions helps to reduce the viral load of SARS-CoV-2 in the environment, and consequently the airborne transmission of COVID-19 is limited.

Keywords: COVID-19; SARS-CoV-2; airborne transmission; air ionization.

1 Universidad de Sonora, Correo: jesus.pacheco@unison.mx 


\section{INTRODUCCIÓN}

Las enfermedades infecciosas como la Influenza y coronavirus (COVID-19) causan millones de muertes alrededor del mundo [1], [2]. Los patógenos de tales enfermedades son propagados principalmente por pequeñas gotas o aerosoles como resultado de tos, estornudos, etc [3]. A causa de la situación de pandemia originada por el Coronavirus de tipo 2 causante del Síndrome Respiratorio Agudo Severo (SARS-CoV-2, por sus siglas en inglés), existe la necesidad urgente de limitar la transmisión aérea del COVID-19. Este artículo se enfoca en un dispositivo denominado SafeAir-1200 basado en la ionización del aire (ver Figura 1) y diseñado específicamente para dicho propósito.

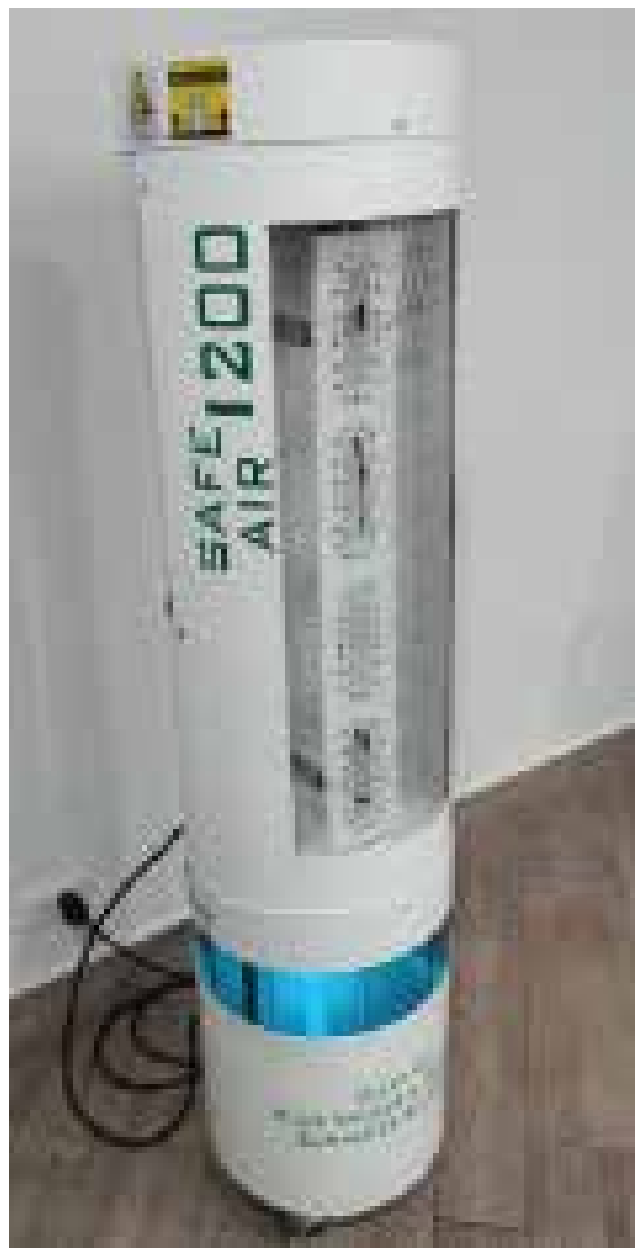

Figura 1. Safe Air 1200, dispositivo para la limpieza del aire por ionización.

\section{PLANTEAMIENTO DEL PROBLEMA}

Algunas soluciones convencionales como limpiadores de aires se encuentran bajo evaluación para probar su capacidad en escenarios relevantes [4], sin embargo, esos sistemas no han sido probados en entornos tales como hospitales, con carga viral confirmada de SARS-CoV2. La diseminación de patógenos infecciosos en hospitales puede ser significativa y, en varios escenarios, el requisito es contar con un ambiente libre de patógenos (por ejemplo, en quirófanos) no sólo para protección de pacientes sino también del personal del hospital [5]. Se ha demostrado que la generación de iones negativos puede reducir la transmisión de enfermedades debido a patógenos como virus [6] y bacterias [7]. Lo anterior obedece a que las partículas cargadas se unen con las que no lo están por atracción electrostática [8] formando un cuerpo pesado que colapsa rápidamente al suelo.

\section{OBJETIVO}

El objetivo de este trabajo es demostrar la efectividad del dispositivo para limitar la transmisión aérea del COVID-19 por medio de la generación de iones negativos.

\section{MÉTODO DE TRABAJO}

A continuación, se presentan los materiales y métodos para mostrar la capacidad del dispositivo propuesto en limitar la transmisión aérea del COVID-19. Primeramente, se explica en términos generales el diseño del dispositivo, después se detallan los procedimientos para probar su efectividad en el ambiente controlado y finalmente, se describe el procedimiento aplicado en una institución de salud.

\section{Safe Air 1200}

La estructura del dispositivo consta de un cilindro fabricado en acero y policarbonato. La Figura 2 muestra el esquemático para el dispositivo.
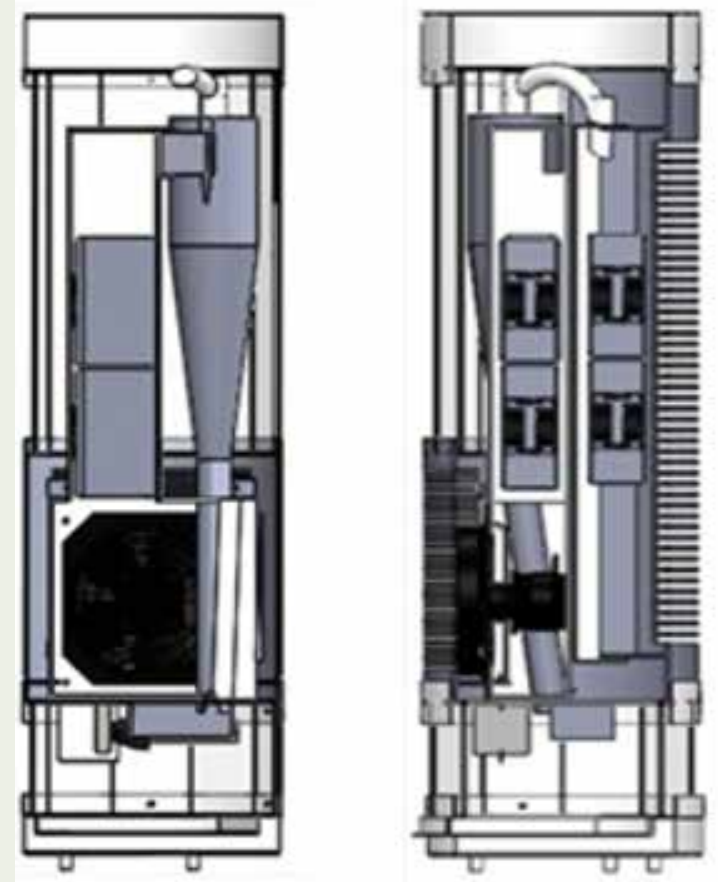

Figura 2. Vista esquemática del dispositivo, a) Vista posterior, b) Vista lateral. 


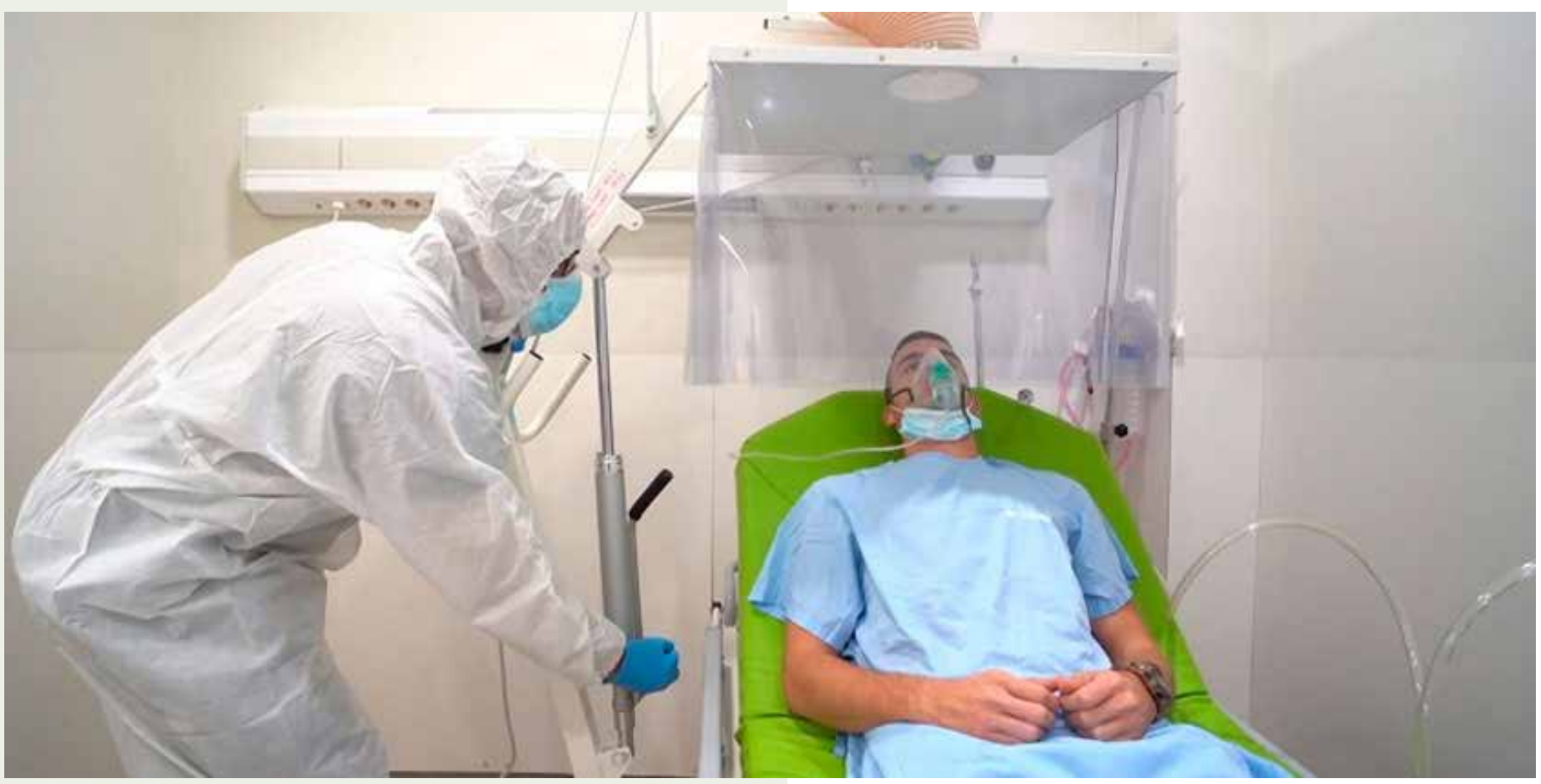

La parte posterior del dispositivo contiene un ventilador que circula el aire a través de una estructura con forma de embudo para mezclar partículas pesadas con ligeras creando un cuerpo pesado que colapsa dentro del embudo hacia una cámara de servicio equipada con una lámpara UV-C para ayudar a inhabilitar los patógenos capturados. El embudo se comunica con el área frontal para entregar el aire al ambiente.

Debajo de la cámara de servicio se encuentra una cámara aislada equipada con generadores de alto voltaje con la capacidad de generar hasta $1680 \times 10^{6}$ iones, medido a $1 \mathrm{~cm}$ con el DLY-3 Air lon Counter. Para generar tal cantidad de iones, el voltaje generado es llevado al área frontal, utilizando cepillos de fibra de carbono como terminales.

Otro aspecto analizado fue la emisión de ondas electromagnéticas que pueden interferir con otros dispositivos en los alrededores del Safe Air 1200. Se analizaron los dispositivos más comunes, incluyendo computadoras, puntos de acceso, monitores de oxígeno, dosímetros y celulares. Los dispositivos muestran un comportamiento normal al estar $50 \mathrm{~cm}$ separados (en todas direcciones), sin embargo, algunas comunicaciones (por ejemplo, Wi-Fi) son afectadas a $30 \mathrm{~cm}$ del dispositivo. La afectación es mayormente en la potencia de la señal, sin mostrar efectos en pérdida de datos (verificado con un osciloscopio Tektronix).

\section{Ambiente controlado}

El ambiente controlado, mostrado en la Figura 3, consiste en una cámara sellada cerrada de $2.20 \mathrm{~m} \mathrm{x}$ $2.20 \mathrm{~m} \times 3.70 \mathrm{~m}$ (17.90 metros cúbicos). Fue construida específicamente para realizar pruebas con aerosoles conteniendo patógenos y humo. La cámara está equipada con conductos especiales para inyección y extracción de aerosoles, humo y otras partículas, además de varias escotillas para acceder de manera segura al interior en caso de ser requerido.

Para medir la carga de partículas en el ambiente, se utilizó un sensor láser con capacidad para medir partículas en tamaños de 1, 2.5 y 10 micrones para alinearse a estudios previos [1], [4], [10]. Partículas por debajo de 1 micrón no cuentan con una carga viral significativa y mayores a 10 micrones colapsarán más rápido [8], es por ello por lo que no se muestran en este trabajo.

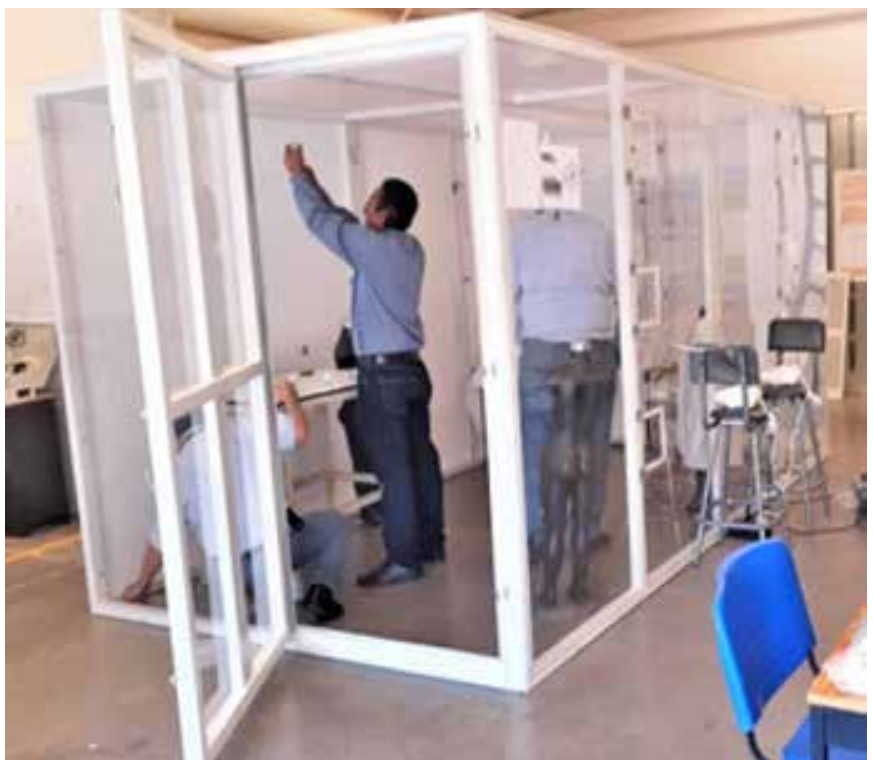

Figura 3. Cámara pruebas en ambiente controlado. Institución de salud con casos confirmados de COVID-19 




\section{Resultados en Institución de salud}

La primera prueba se llevó a cabo sin el dispositivo. Los resultados muestran que el SARS-CoV-2 sólo se encontró en el segundo piso (área COVID). La Figura 8 muestra la preparación en la calibración en uno de los pasillos de la clínica.

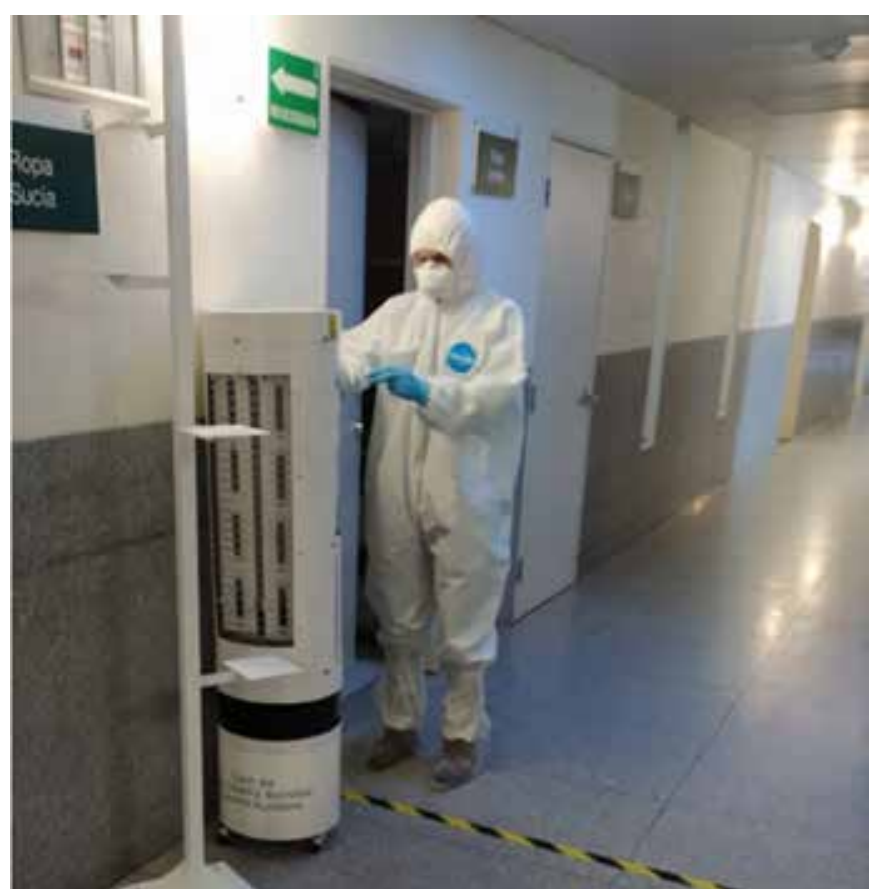

Figura 8. Preparación del dispositivo en la institución de salud (pasillo).

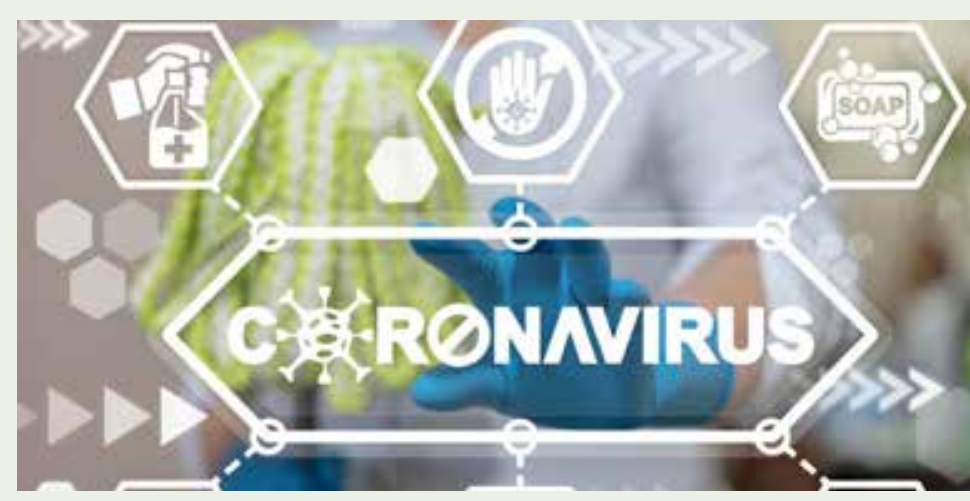

En un inicio se detectó PM de bacterias en el ambiente, un marcador de calidad biológico del aire [13], lo cual significa que otros patógenos pueden ser reproducidos en el área donde se encuentran las bacterias.

La segunda prueba fue realizada con el dispositivo en donde se detectó el SARS-CoV-2. El área por cubrir fue de $6 \mathrm{~m} \times 3 \mathrm{~m}$, y el dispositivo fue puesto en funcionamiento 30 minutos antes de comenzar el proceso de muestreo, sin embargo, solamente se requirieron 10 minutos para manifestar menos de 5 microgramos $/ \mathrm{m}^{3}$ en el ambiente. Para esta prueba, el SARS-CoV-2 fue detectado en menor concentración, se estima que el $80 \%$ de la carga viral fue eliminada del ambiente. Sin embargo, no fue posible buscar el virus en el suelo del área COVID de la institución para argumentar que se eliminó el virus. Como se puede observar en la Figura 9, el tiempo para reducir la concentración de partículas en el aire para la institución de salud fue de 5 minutos. 


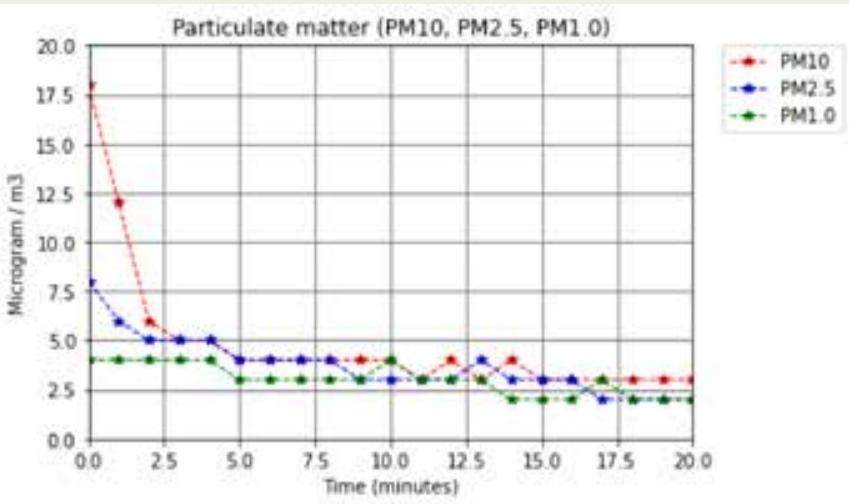

Figura 9. Concentración de partículas en la institución de salud bajo la influencia del dispositivo.

\section{DISCUSIÓN}

Las Figuras 4 y 5 correspondientes a las pruebas en ambiente controlado, muestran que el dispositivo puede reducir partículas suspendidas en el aire al influenciar a tales partículas a unirse entre ellas. Como se puede observar en la Figura 4, las partículas de 10, 2.5 y 1 micrómetros permanecen en el medio ambiente de forma natural durante al menos 20 minutos, sin embargo, bajo la acción del dispositivo, la cantidad de partículas suspendidas se redujo a menos de 5 microgramos $/ \mathrm{m}^{3}$ (Ver Figura 5), lo que significa que el dispositivo afecta a las partículas en un ambiente cerrado en al menos un $98 \%$, tomando en consideración el peor de los casos el cual es $\mathrm{PM}_{10}$ partículas, empezando a 120 microgramos $/ \mathrm{m}^{3}$ y finalizando a 2 microgramos $/ \mathrm{m}^{3}$.

También fue evaluada la capacidad del dispositivo para reducir patógenos en el ambiente. La Figura 7 muestra que la bacteria Vibrio parahaemolyticus puede permanecer suspendida en el aire durante al menos 7 horas, sin embargo, bajo la influencia del dispositivo, la cantidad de bacteria se redujo drásticamente al punto de no encontrar colonias después de 20 minutos de exposición.

Para cumplir con el objetivo de este trabajo, el dispositivo fue probado en una institución de salud con casos confirmados de COVID-19, de las áreas muestreadas, sólo en el área COVID se pudo detectar SARS-CoV-2, lo que significa que los protocolos de sanitización y aislamiento seguidos en la institución son efectivos. En elárea señalada, el tiempo para reducir la concentración de partículas del aire es de cerca de 5 minutos, esto se debe a que el ambiente real no se encuentra saturado de partículas, lo cual potencia la efectividad del dispositivo para limitar la transmisión aérea del COVID-19.

Trabajos previos [6], [8] señalan que es posible limitar el contagio de virus como el de la influenza utilizando ionización, sin embargo las investigaciones y experimentos mostrados se limitan a ambientes controlados y de poco volumen, por lo que el presente trabajo demuestra que es posible ajustar los procedimientos planteados en la literatura para ambientes abiertos o no controlados.

\section{CONCLUSIONES}

Algunos hallazgos de este trabajo se pueden enumerar de la siguiente manera:

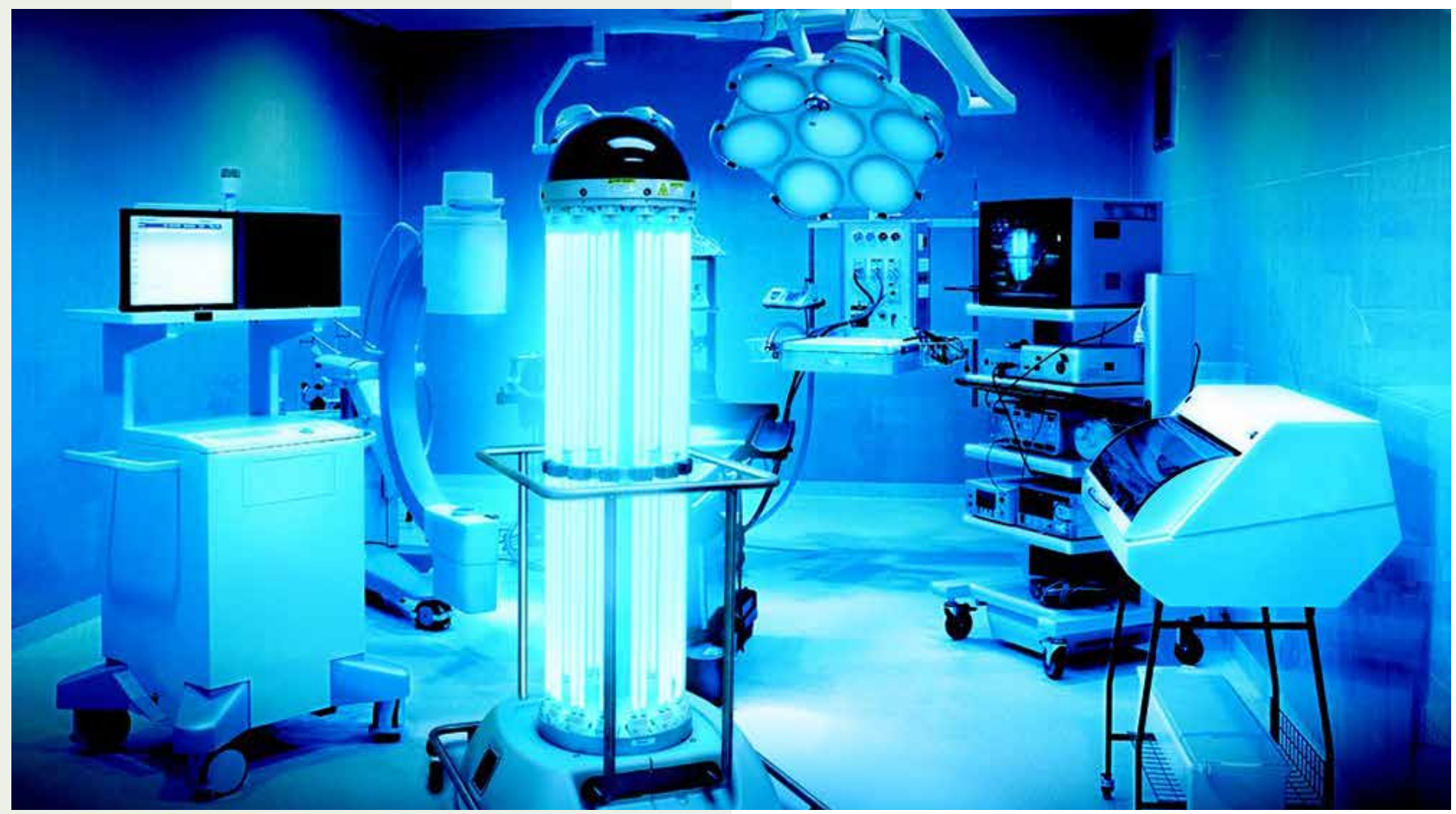


De acuerdo con los experimentos, el SARS-CoV-2 puede adherirse al PM del ambiente que generalmente presenta tamaños entre 1 y 10 micrómetros $\left(\mathrm{PM}_{10} \mathrm{PM}_{2.5}\right.$ y $\mathrm{PM}_{10}$ ). Con esta información, se puede concluir que, para entornos cerrados, el virus puede permanecer en el aire durante al menos 7 horas.

Una alta densidad de iones negativos ayuda en reducir el PM en el aire y, como consecuencia, ayuda a reducir la transmisión aérea de virus como el SARS-CoV-2.

La presencia de PM de bacterias en el ambiente representa un marcador de calidad biológico del aire.

\section{Futuras investigaciones}

El tiempo para realizar las pruebas en la institución de salud fue limitado por cuestiones de seguridad. Existe una necesidad urgente de confirmar los hallazgos de esta investigación en un entorno relevante con casos confirmados de COVID-19, teniendo más tiempo y áreas para inspeccionar, por ejemplo, un quirófano, el cual se supone debe encontrarse libre de patógenos.

Se requiere otra investigación para verificar si el ambiente puede ser estabilizado en el mismo lapso, considerando tráfico regular (personal caminando en los alrededores).

\section{RECONOCIMIENTO}

Proyecto apoyado por el Consejo Nacional de Ciencia y Tecnología (CONACyT) con número 312541.

\section{BIBLIOGRAFÍA}

[1] N.I. Stilianakis, Y. Drossinos, "Dynamics of infectious disease transmission by inhalable respiratory droplets," Journal of the Royal Society Interface, vol. 7(50), pp. 1355-1366, April 2010.

[2] I. Çelik, E. Saatçi, A. F. Eyüboğlu, "Emerging and reemerging respiratory viral infections up to Covid-19,"Turkish Journal of Medical Sciences, vol. 50(SI-1), pp. 557-562, April 2020.

[3] M. Lipsitch, T. Cohen, B. Cooper, J. M. Robins, L. James, G. Gopalakrishna, S. K. Chew, C. C. Tan, M. H. Samore, D. Fisman, M. Murray, "Transmission dynamics and control of severe acute respiratory syndrome," Science, vol. 300(5627), pp. 1966-1970, June 2003.

[4] J. H. Sung, Y. Lee, B. Han, Y. J. Kim, H. J. Kim, “Improvement of particle clean air delivery rate of an ion spray electrostatic air cleaner with zero-ozone based on diffusion charging," Building and Environment, vol. 186(107335), December 2020.

[5] R. M. Blackburn, D. Frampton, C. M. Smith, E. B. Fragaszy, S. J. Watson, R. B. Ferns, S. Binter, P. G. Coen, P. Grant, L. J. Shallcross, Z. Kozlakidis, D. Pillay, P. Kellam, S. Hué, E. Nastouli, A. C. Hayward, "Nosocomial transmission of influenza: A retrospective cross-sectional study using next generation sequencing at a hospital in England (2012-2014)," Influenza and Other Respiratory Viruses, Vol. 13(6), pp. 556-563, September 2019.

[6] T. Estola, P. mäkelä, T. Hovi, "The effect of air ionization on the air-borne transmission of experimental Newcastle disease virus infections in chickens," Epidemiology \& Infection, vol. 83(1), pp. 59-67, August 1979.

[7] A. R. Escombe, D. A. J. Moore, R. H. Gilman, M. Navincopa, E. Ticona, B. Mitchell, C. Noakes, C. Martínez, P. Sheen, R. Ramirez, W. Quino, A. Gonzalez, J. S. Friedland, C. Evans,
"Upper-room ultraviolet light and negative air ionization to prevent tuberculosis transmission," PLOS Medicine, vol. 6(3), March 2009.

[8] M. Hagbom, J. Nordgren, R. Nybom, K. O. Hedlund, H. Wigzell, L. Svensson, "lonizing air affects influenza virus infectivity and prevents airborne-transmission," Scientific reports, vol. 5(11431), June 2015.

[9] D. B. Day, J. Xiang, J. Mo, F. Li, M. Chung, J. Gong, C. J. Weschler, P. A. Ohman-Strickland, J. Sundell, W. Weng, Y. Zhang, J. Zhang, "Association of ozone exposure with cardiorespiratory pathophysiologic mechanisms in healthy adults," JAMA Internal Medicine, vol. 177(9), pp. 1344-1353, September 2017.

[10] W. Liu, J. Huang, Y. Lin, C. Cai, Y. Zhao, Y. Teng, J. Mo, L. Xue, L. Liu, W. Xu, X. Guo, Y. Zhang, "Negative ions offset cardiorespiratory benefits of $\mathrm{PM}_{25}$ reduction from residential use of negative ion air purifiers," International Journal of Indoor Environment and Health, vol. 31, pp. 220-228, August 2020.

[11] J. Moreno-Contreras, M. A. Espinoza, C. Sandoval-Jaime, M. A. Cantú-Cuevas, H. Barón-Olivares, O. D. Ortiz-Orozco, A. V. Muñoz-Rangel, M. Hernández-de la Cruz, C. M. Eroza-Osorio, C. F. Arias, S. López, "Saliva sampling is an excellent option to increase the number of SARS CoV2 diagnostic tests in settings with supply shortages," bioRxiv, preprint, July 2020.

[12] H. Hauck, "Revision of ambient air quality standards for PM?", Toxicology letters, vol. 96, pp. 269-276, August 1998.

[13] R. A. Santos, N. J. Sau, M. T. Certucha, F. J. Almendáriz, A. O. Monge, I. J. Zepeda, L. J. Hernández, "Rapid detection of bacteria, Enterococcus faecalis, in airborne particles of Hermosillo, Sonora, México," Journal of Environmental Biology, vol. 40, pp. 619-625, July 2019.

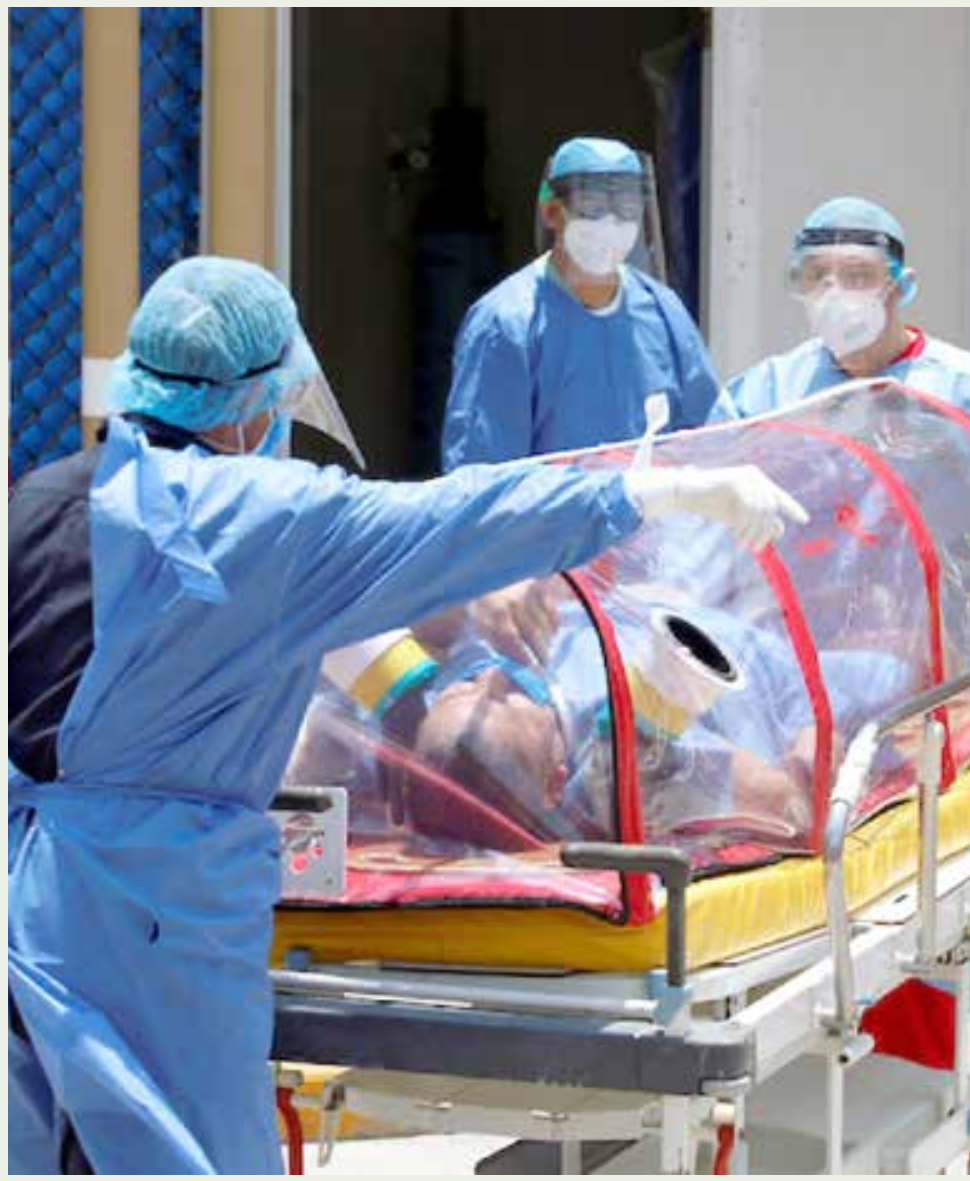

